\begin{tabular}{r|l|l|l}
$\begin{array}{c}\text { Case Reports in } \\
\text { Gastroenterology }\end{array}$ & $\begin{array}{l}\text { Case Rep Gastroenterol 2010;4:335-339 } \\
\text { DOl: 10.1159/000320670 }\end{array}$ & $\begin{array}{l}\text { Published online: } \\
\text { September 13, 2010 }\end{array}$ & $\begin{array}{l}\text { O 2010 S. Karger AG, Basel } \\
\text { ISSN 1662-0631 } \\
\text { www.karger.com/crg }\end{array}$ \\
\hline
\end{tabular}

This is an Open Access article licensed under the terms of the Creative Commons AttributionNonCommercial-NoDerivs 3.0 License (www.karger.com/OA-license), applicable to the online version of the article only. Distribution for non-commercial purposes only.

\title{
The Returning Traveller: Dengue Fever Report
}

\section{Gemina Doolub}

Acute General Medicine, John Radcliffe Hospital, Oxford, UK

\section{Key Words}

Fever - Diarrhoea $\cdot$ Infectious disease

\begin{abstract}
This report describes a 21-year-old male patient who presented to a UK hospital with mild symptoms of fever, malaise and arthralgia. He had just returned from Hoga Islands (Indonesia) where he had spent six weeks. While examination was unremarkable, his blood showed a significant rise in liver function tests and a steady drop in white cells as well as platelets. Dengue serology was later found to be positive for anti-Dengue IgG as well as IgM. With supportive treatment, this young gentleman recovered quickly and was discharged with a plan for follow-up in the clinic.
\end{abstract}

\section{Case Report}

Mr. S.C., 21 years old, was admitted to a UK hospital feeling 'increasingly unwell' for 10 days. Among his presenting features were the following: fever, generalised joint ache, loss of appetite, malaise, dizziness and mild diarrhoea, including one episode of fresh rectal bleeding. He was otherwise well and denied other symptoms such as abdominal pain, nausea or vomiting, cough, photophobia or rashes. Prior to this Mr. S.C. had been fit and healthy with no past medical history. He was studying marine biology at University, was a non-smoker and drank only social alcohol. There was no significant family history. He had come back three days earlier from a six-week trip to Hoga Islands (Indonesia) where he had been doing biomarine research. Risk factors elicited were the following: (1) He had stopped taking his antimalarial tablets two weeks into the trip. (2) He had been drinking water from a well. (3) He had been diving in salt water. He denied any risk of sexually transmitted disease or intravenous drug use.

On examination, Mr. S.C. was pyrexial with a temperature of $38.6^{\circ} \mathrm{C}$. His pulse was $80 \mathrm{bpm}$ and regular, blood pressure $131 / 72 \mathrm{~mm} \mathrm{Hg}$, respiratory rate $18 / \mathrm{min}$ and saturation on air $97 \%$. His chest was clear, and normal heart sounds with no added murmurs could be heard on auscultation. His abdomen was soft and non-tender, and there was no evidence of any hepatosplenomegaly. Neurological examination was unremarkable and there was no peripheral oedema.

\section{Investigations}

Blood tests on admission were unremarkable apart from a raised CRP of 32 and a creatinine of 126. The following days eventually showed a particular trend in white cell count and platelet count, steadily dropping until August 31st, when Mr. S.C. was discharged (ig. 1, fig. 2 ). This was accompanied by a 


\begin{tabular}{r|l|l|l} 
Case Reports in & $\begin{array}{l}\text { Case Rep Gastroenterol 2010;4:335-339 } \\
\text { DOl: 10.1159/000320670 }\end{array}$ & $\begin{array}{l}\text { Published online: } \\
\text { September 13, 2010 }\end{array}$ & $\begin{array}{l}\odot \text { ISSN 1662-0631 } \\
\text { www.karger.com/crg }\end{array}$ \\
\hline
\end{tabular}

contrasting rise in ALT over the same period of time (fig. 3). Investigations requested at that stage were as follows: chest X-ray: normal; thick and thin films (x3): all normal; stool MCS: normal; blood cultures: normal; hepatitis screen: negative; serology for typhoid, cytomegalovirus, and Epstein-Barr virus; serology for Dengue fever.

\section{Differential Diagnosis}

Malaria was first on the list of differentials to be excluded, given the combination of fever, diarrhoea and the fact that S.C. had stopped taking his antimalarial tablets two weeks into the trip. We were particularly worried about the possibility of Plasmodium falciparum, especially virulent, as it can cause end-organ damage to the central nervous system, kidneys and lungs. However, the absence of splenomegaly as well as the negative blood films made it less likely. Again top on the list of differentials was Dengue fever as it is endemic to Indonesia. Furthermore, the fever and arthralgia, accompanied by the raised LFTs and leucopenia, were all strongly suggestive of Dengue fever. However, there was no hepatomegaly or classical maculopapular rash often associated with the condition. In the UK, typhoid fever (also known as enteric fever), caused by the Gram-negative bacterium Salmonella typhi, is mostly seen in travellers returning from India. Typical features are a stepwise fever accompanied by relative bradycardia and a 'rose spots' rash on the torso. Swine flu needed to be excluded since Aylesbury has been a hotspot for the outbreak. Hepatitis was suspected as suggested by the deranged LTFs, fever and suspicious oral intake during the trip.

\section{Treatment}

Dengue was eventually confirmed by isolation of the virus in serum and detection of immunoglobulins (IgM as well as a five-fold increase in IgG titre) by enzyme-linked immunosorbent assay antibody capture. Treatment was mainly supportive, in the form of intravenous fluids and paracetamol. Transfusion was not required since the platelet count was above $20 \times 10^{9} / 1$, the current threshold for transfusion.

\section{Outcome and Follow-Up}

As he started feeling better and his blood values were improving, Mr. S.C. was discharged after a week of hospitalisation. Second Dengue serology eventually came back again positive for IgG. Mr. S.C. came back a month later for an outpatient follow-up, and by that time his blood count as well as his biochemistry had normalised.

\section{Discussion}

Dengue fever is caused by one of the single-stranded RNA viruses of the Flavivirus genus. It represents the most common cause of arboviral disease (viruses transmitted by arthropods) and is endemic to the tropics. The incidence of Dengue fever is as high as 50-100 million annually worldwide, and it is transmitted by the Aedes aegypti mosquito. There are four main Dengue virus serotypes; infection with one serotype produces lifelong immunity only to that serotype. Humans and mosquitoes are the principal hosts, and illness is only ever manifested in humans $[1,2]$. Dengue fever has been on the rise lately due to several factors, namely: (1) population growth in the tropics; (2) poor management of waste and water in urban areas; (3) an increase in air travel, meaning humans import more viruses; (4) the fact that Dengue tends to be under-reported as it is not notifiable in most countries and often not diagnosed. Dengue fever has an incubation period of 3-14 days (normally 5-7). Humans with Dengue can pass it to other humans only via mosquitoes or blood products and only whilst febrile. 


\begin{tabular}{r|l|l|l}
$\begin{array}{c}\text { Case Reports in } \\
\text { Gastruanteriology }\end{array}$ & $\begin{array}{l}\text { Case Rep Gastroenterol 2010;4:335-339 } \\
\text { DOI: 10.1159/000320670 }\end{array}$ & $\begin{array}{l}\text { Published online: } \\
\text { September 13, 2010 }\end{array}$ & $\begin{array}{l}\text { O 2010 S. Karger AG, Basel } \\
\text { ISSN 1662-0631 } \\
\text { www.karger.com/crg }\end{array}$ \\
\hline
\end{tabular}

Clinical features can include any of the following: abrupt onset high fever (biphasic the second fever occurs approximately 7 days after onset, after defervescence); severe headache; myalgia (breakbone fever); arthralgia; nausea, vomiting and diarrhoea; dizziness; loss of appetite; sore throat; cough; cutaneous hyperaesthesia; taste disturbance. Other features typically described involve: a rash in 50\% of cases which is macular/ maculopapular with islands of sparing; flushed facies, effusions, ascites, and finally, hepatomegaly in up to $40 \%$ of patients.

Laboratory features suggestive of Dengue fever are: leucopenia; neutropenia; lymphocytosis; raised LFTs; thrombocytopenia (platelet count $<100 \times 10^{9} / 1$ ); increased haematocrit; platelet count that tends to drop until temperature returns to normal [3].

The previous classification of Dengue as outlined by the World Health Organisation subdivided Dengue into 5 different categories, namely: (1) non-specific febrile illness; (2) classic Dengue; (3) Dengue haemorrhagic fever; (4) Dengue haemorrhagic fever with Dengue shock syndrome; (5) other unusual syndrome, e.g. encephalopathy [4-6]. It is very important to realise that this classification no longer holds true, as there have been several reports of difficulties in its use which were summarised in a systematic literature review $[7,8]$. A new model for classifying Dengue has been recommended by a specialist group (Geneva, Switzerland, 2008) and has been tested in 18 countries. The new suggested dengue case classification and levels of severity are outlined below [9].

Criteria for probable Dengue include: live in/travel to a Dengue endemic area; fever and two of the following criteria: nausea, vomiting; rash; aches and pains; tourniquet test positive; leukopenia; any warning sign. Warning signs would include any of: abdominal pain or tenderness; persistent vomiting; clinical fluid accumulation; musocal bleed; lethargy or restlessness; liver enlargement $>2 \mathrm{~cm}$; increase in haematocrit concurrent with rapid decrease in platelet count.

Criteria for severe Dengue include: severe plasma leakage leading to shock or fluid accumulation with respiratory distress; severe bleeding as evaluated by the clinician; severe organ involvement with: liver: AST or ALT > 1,000; CNS: reduced consciousness; heart and other organ involvement $[10,11]$.

Furthermore, depending on clinical presentation, patients are divided into 3 groups. Group A: These are patients who do not have any warning signs and may be sent home on oral fluids. Group B: These patients, who have warning signs, should be admitted to a secondary health care centre for close monitoring as they approach the critical phase. The immediate management includes obtaining a reference haematocrit prior to fluid therapy, initiating isotonic solution infusion, and re-assessing the haematocrit regularly. Group C: These individuals require emergency treatment as they present with severe Dengue as described earlier. As can be gathered from the above information, our patient would fit in category $\mathrm{B}$, which is why he was admitted to hospital for intravenous rehydration as well as close monitoring.

\section{Learning Points/Take Home Messages}

(1) Dengue fever needs to be excluded in any returning traveller presenting with fever and malaise. (2) The diagnosis of Dengue fever would be suggested by leucopenia, thrombocytopenia and raised liver function tests. It is however confirmed by the presence 


\begin{tabular}{r|l|l|l}
$\begin{array}{c}\text { Case Reports in } \\
\text { Gastruanteriology }\end{array}$ & $\begin{array}{l}\text { Case Rep Gastroenterol 2010;4:335-339 } \\
\text { DOI: 10.1159/000320670 }\end{array}$ & $\begin{array}{l}\text { Published online: } \\
\text { September 13, 2010 }\end{array}$ & $\begin{array}{l}\text { O 2010 S. Karger AG, Basel } \\
\text { ISSN 1662-0631 } \\
\text { www.karger.com/crg }\end{array}$ \\
\hline
\end{tabular}

of IgG and IgM antibodies in serum. (3) Supportive management is the mainstay of treatment for complications such as Dengue haemorrhagic fever and Dengue shock syndrome. (4) The previous WHO classification of Dengue has been replaced by a clearer, much simplified version to help and guide management by healthcare professionals. (5) What is current knowledge: Dengue fever can deteriorate alarmingly fast with haemorrhagic manifestations, severe nausea and vomiting. (6) What is new here: Dengue fever can also follow a surprisingly mild course initially, but it is important to rapidly diagnose the illness so as to start the mainstay of supportive therapy efficiently, before the patient gets compromised. The article also describes the new WHO classification and its implication for treatment of patients presenting with features suggestive of Dengue.

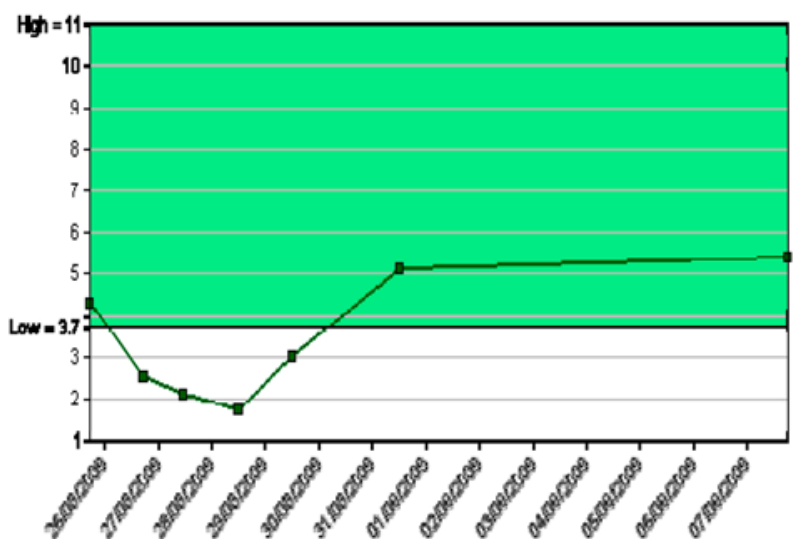

Fig. 1. White cells: trend with time.

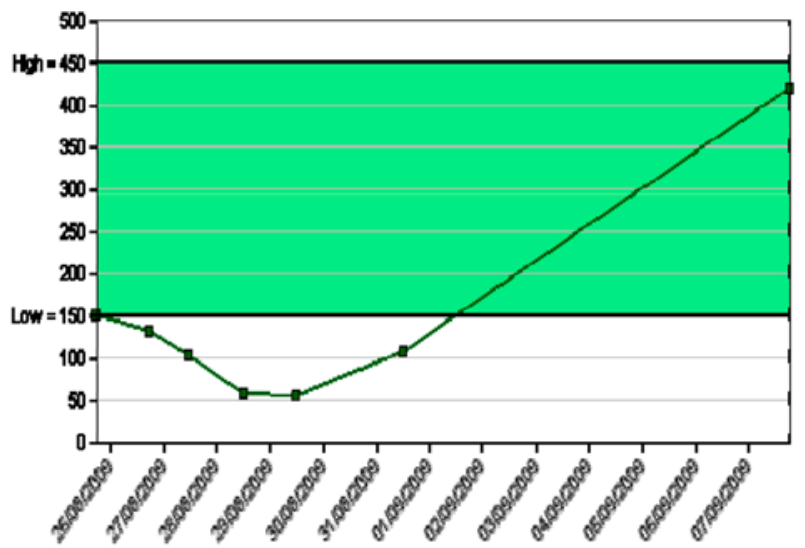

Fig. 2. Platelets: trend with time. 


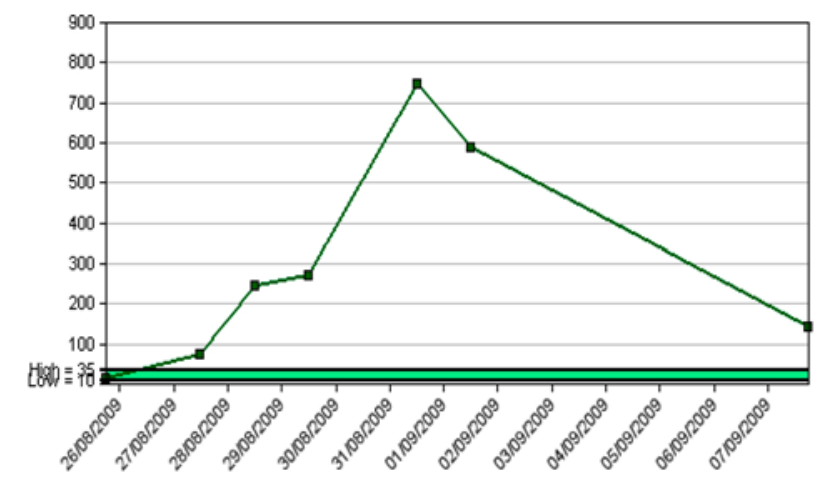

Fig. 3. ALT: trend with time.

\section{References}

1 Malavige GN, Fernando S, Fernando DJ, et al: Dengue viral infections. Postgrad Med J 2004;80:588-601.

$>2$ Schwartz E, Mendelson E, Sidi Y: Dengue fever among travellers. Am J Med 1996;101:516-520.

-3 Monath TP: Dengue and yellow fever - challenges for the development and use of vaccines. N Engl J Med 2007;357:2222-2225.

4 Rigau Pérez J, Clark GG, Gubler DJ, Reiter P, Sanders EJ, Vorndam AV: Dengue and Dengue hemorrhagic fever. Lancet 1998;352:971-977.

5 Guzman MG, Kouri G: Dengue: an update. Lancet Infect Dis 2002;2:33-42.

6 Dengue Haemorrhagic Fever: Diagnosis, Treatment, Prevention and Control, ed 2. Geneva, World Health Organization, 1997. http://www.who.int/csr/resources/publications/dengue/Denguepublication/en/print.html.

7 Deen JL, Harris E, Wills B, et al: The WHO Dengue classification and case definitions: time for a reassessment. Lancet 2006;368:170-173.

8 Bandyopadhyay S, Lum LC, Kroeger A: Classifying Dengue: a review of the difficulties in using the WHO case classification for dengue haemorrhagic fever. Trop Med Int Health 2006;11:1238-1255.

9 World Health Organisation (2010): Dengue. www.who.int/topics/dengue/en (accessed February 2010).

10 Gubler DJ: Epidemic Dengue/Dengue hemorrhagic fever as a public health, social and economic problem in the 21st century. Trends Microbiol 2002;10:100-103.

11 Roehrig JT: Immunochemistry of viruses; in Gubler DJ, Kuno G (eds): Dengue and Dengue Hemorrhagic Fever. New York, CAB International, 1997, pp 199-219. 